\title{
Evaluating On-Road Emissions Impacts of HEVs, PHEVs and EVs: An Integrated Modeling Framework
}

\author{
Kejia Hu', Jianyou Zhao², Yuche Chen ${ }^{3}$, L.D. White ${ }^{4}$ \\ ${ }^{1}$ Owen School of Management, Vanderbilt University, Nashville, Tennessee 37235, United States \\ ${ }^{2}$ Chang'an University, Xi'an, China \\ ${ }^{3}$ Department of Civil and Environmental Engineering, Vanderbilt University, Nashville, Tennessee 37235, United States \\ ${ }^{4}$ Texas A\&M Transportation Institute, Texas A\&M University, Campus Box 3135, College Station, Texas 77843, United States
}

\begin{abstract}
This paper develops a framework to evaluate HEVs, PHEVs and EVs on-road emissions impact, by integrating endogenous vehicle consumer choice model and MOVES-based regional emission transportation model. A case study based on Harris County, Texas data is implemented to examine the on-road emissions under different market penetrations (due to different future energy price) and government policies. The results show different on-road transportation emissions level for Carbon Dioxide $\left(\mathrm{CO}_{2}\right)$, Carbon Monoxide $(\mathrm{CO})$, Nitrogen Oxide $\left(\mathrm{NO}_{\mathrm{x}}\right)$ and Total Hydrocarbon (THC). In addition, cost effectiveness of reducing on-road emissions by extending tax credit for plug-in electric vehicles (PEV) is calculated and reported.
\end{abstract}

Keywords: Emission Impacts Analysis; Consumer Choice Model; On-road Emission

\section{Introduction}

Transportation sector is a big energy consumer, and one of the largest Greenhouse Gas and air pollution contributor. In U.S., transportation sector accounts for $28.1 \%$ of GHG emission (EPA, 2013), 54\% of carbon monoxide (CO), 61\% of nitrogen oxides $\left(\mathrm{NO}_{\mathrm{x}}\right)$, and $24 \%$ of volatile organic compounds (VOCs) emissions in 2012 (EPA, 2013). In Asia, transportation sector contributes $22 \%$ of total $\mathrm{CO}_{2}$ emissions and the contribution is expected to keep increasing given the projected increasing automobile ownership in Asian counties (IEA, 2012).

Governments around the world are taking steps to address the energy and air pollution problems cause by transportation (CARB, 2014; U.S. DOE, 2011; European Parliament, 2011; Chen et al., 2013; Morrison and Chen, 2011). One possible way is through expanding penetration of electric vehicle in private and public transportation sector. Alternative Fuel Vehicles (AFVs) are becoming increasingly accessible to the general public with the expansion of supporting infrastructure and financial incentives offered by state and federal governments(Nichols et al., 2009). Future market penetration for commercial AFVs will continue to increase as the price of fuel increases and as sustainability and air quality policies become a more substantial public concern (Yabe et al., 2010; Baptista et al., 2010; Propfe et al., 2013; Yang et al., 2014).

Widespread adoption of AFVs may substantially reduce emissions of greenhouse gases while improving regional air quality, increasing energy security, and taking advantage of alternative energy. Some studies developed methods to Evaluate AFVs' GHG and air quality impacts (Millo et al., 2014; Zhou et al., 2013; Ford, 1995; Hawkins et al., 2012; Kammen et al., 2002). However, few of them focus on regional level analysis and AFVen for those studies; majority of them focused on greenhouse gas emissions without considering criteria pollutants (e.g. CO, VOCs, and $\mathrm{NO}_{\mathrm{x}}$ ). $\mathrm{Kim}_{\mathrm{m}}$ and Rahimi Evaluated GHG emissions impacts of large-scale adoption of AFVs in Los Angeles (Kim et al., 2014). The 
study found that by year 2030, a large-scale adoption of AFVs will lead to significant increase in power generation loads and result in various increases in GHG emissions depending on AFVs' charging behavior. Thompson et al. analyzed air quality impacts of AFVs in four major cities in Texas (Thompson et al., 2011). They found that plug-in electric vehicles (PHEVs) lead to an increase in ozone during nighttime hours and a decrease in ozone during daytime hours. Both of the studies focus on AFVs' grid emissions instead of on-road emissions impacts which are critical to transportation planning agencies on transportation conformity type analysis. Transportation conformity is a process required by the U.S. Clean Air Act (CAA) to ensure transportation funding and activities in areas which do not meet air quality standards to be consistent with air quality goals. Based on our best knowledge, none existing literature provide a realistic method to incorporate AFVs into regional on-road transportation emission analysis.

In this study, we demonstrate a modeling framework to evaluate AFVs' GHG and air quality impacts by integrating an endogenous electric vehicle consumer choice model and link-based emission inventory model. Market Acceptance of Advanced Automotive Technologies $\left(\mathrm{MA}^{3} \mathrm{~T}\right)$ model is selected as an automobile market consumer choice model considering endogenous parameters such as future energy price and government policies. We use a link-based emission inventory model, "MOVESemscalc", which is an inventory utility based on U.S. Environmental Protection Agency's (EPA) Motor Vehicle Emission Simulator (MOVES) platform. A case study is conducted to Harris County, Texas due to its large population (and still growing) and located in a major nonattainment area, where air quality is a concern.

\section{Methodology}

An approach which integrates a vehicle consumer choice model and a link-based emission model is developed to assess AFVs' emissions impacts in transportation emissions analysis (see Figure 1). The emission pollutants Evaluated are Carbon Dioxide $\left(\mathrm{CO}_{2}\right)$, Carbon Monoxide $(\mathrm{CO})$, Nitric Oxide and Nitrogen Dioxide $\left(\mathrm{NO}_{\mathrm{x}}\right)$, and Total HydroCarbon (THC). The system boundary for this study is limited to on-road exhaust emissions from transportation sector.

First, $\mathrm{MA}^{3} \mathrm{~T}$ model is used to predict AFVs market shares based on future energy price and government policies. The AFVs market shares are then used to calculate AFVs' fleet average emission rates in any analysis year. In addition, based on AFVs market shares, we developed a VMT mix which contains VMT shares of all vehicle types (i.e. MOVES source use type/fuel type, plus AFVs passenger car and passenger truck). Emission rates for AFVs were developed by TTI based on in-use measurements of AFVs tested in College Station, Texas under Texas Department of Transportation (TxDOT) project 0-6763 (Farzaneh et al., 2014). Finally, we apply a link-based emission inventory model, "MOVESemscalc", to estimate on-road exhaust emissions. In this step, VMT mix is applied to disaggregate each link's VMT to each of the vehicle type and then link-level VMT of each vehicle type is multiplied with emission rates to obtain emission estimations.

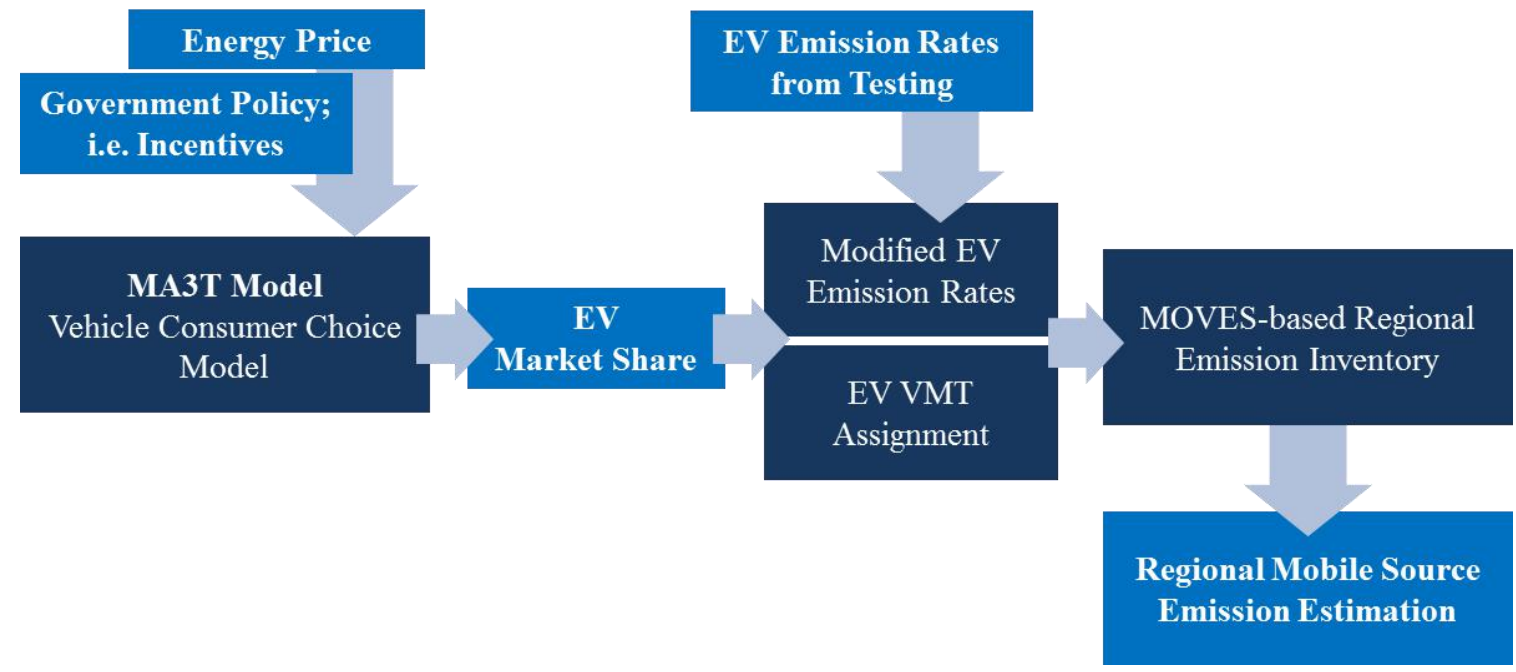

Figure 1; Study Methodology.

This approach is applied to investigate AFVs' impacts under various analysis scenarios on the modeled on-road 
exhaust emissions of greenhouse gas emission (i.e. $\left.\mathrm{CO}_{2}\right)$ and criteria pollutants $\left(\mathrm{CO}, \mathrm{NO}_{\mathrm{x}}\right.$, $\mathrm{THC}$ ) in Harris County of Houston Metropolitan area in year 2026. Harris County was selected because it is the third-most populous county in the United States and locates in Houston-Galveston-Brazoria Area, which is a nonattainment area (previously had not met CAA air quality standard). The available data for year 2026 provide a realistic platform to assess the implication of AFVs to on-road exhaust emissions.

Table 1 shows the descriptions of scenarios developed to assess the on-road exhaust emissions impacts of AFVs at a regional level. As seen in the table, the scenarios vary by analysis year, incorporation of AFVs, and in the assumptions used for the MA3T model where future AFV market penetration is projected. The AFVs considered in this study are hybrid electric vehicle (HEV: Vehicle that employs both an internal combustion engine and an electric motor to provide propulsion), plug-in hybrid electric vehicle (PHEV: Vehicles use part of its power from electric grid via batteries and maintains an alternative energy source onboard to meet propulsion need), and battery electric vehicle (BEV: Vehicles use batteries to store all electricity from power grid and to provide propulsion needs) which are the major AFVs in the market (insert citation). The government policy in the model assumption refers to the $\$ 2,500-7,500$ tax credit (depending on battery capacity) that the U.S. government currently offers to the owners of the first 200,000 plug-in electric vehicles (PEV) from each manufacturer. PEVs are electric vehicles that could be plugged in and charged. PEVs include plug-in hybrid electric vehicles (PHEVs) and battery electric vehicles (BEVs). It is likely that this tax credit will be discontinued several years before 2026(Based on simulations run on MA3T model). An Extended Incentives 2026 scenario is also included to address the impact of extending the government tax credit till the end of 2026.

\begin{tabular}{|c|c|c|c|c|c|}
\hline \multirow[b]{2}{*}{ Scenario } & \multirow[b]{2}{*}{ Year } & \multirow{2}{*}{$\begin{array}{l}\text { EVs in } \\
\text { Fleet }\end{array}$} & \multirow[b]{2}{*}{ EV Market Share Source } & \multicolumn{2}{|c|}{ Assumptions in $\mathbf{M A}^{3} \mathbf{T}$ Model } \\
\hline & & & & Energy Price Source & $\begin{array}{l}\text { Government } \\
\text { Policy in PEV }\end{array}$ \\
\hline Base Case 2026 & 2026 & No & - & - & - \\
\hline $\begin{array}{l}\text { High Oil Price } \\
2026\end{array}$ & 2026 & Yes & $\begin{array}{l}\text { Pre-2014: Historical Sales Data } \\
\text { 2014-2026: Projections from } \mathrm{MA}^{3} \mathrm{~T} \\
\text { model }\end{array}$ & $\begin{array}{l}\text { AEO } 2014 \\
\text { High Oil Price Case }\end{array}$ & $\begin{array}{l}\text { Tax Credits till } \\
2020\end{array}$ \\
\hline $\begin{array}{l}\text { Medium Oil Price } \\
2026\end{array}$ & 2026 & Yes & $\begin{array}{l}\text { Pre-2014: Historical Sales Data } \\
\text { 2014-2026: Projections from } \mathrm{MA}^{3} \mathrm{~T} \\
\text { model }\end{array}$ & $\begin{array}{l}\text { AEO } 2014 \text { Reference } \\
\text { Oil Price Case }\end{array}$ & $\begin{array}{l}\text { Tax Credits till } \\
2020\end{array}$ \\
\hline $\begin{array}{l}\text { Low Oil Price } \\
2026\end{array}$ & 2026 & Yes & $\begin{array}{l}\text { Pre-2014: Historical Sales Data } \\
\text { 2014-2026: Projections from } \mathrm{MA}^{3} \mathrm{~T} \\
\text { model }\end{array}$ & $\begin{array}{l}\text { AEO } 2014 \\
\text { Low Oil Price Case }\end{array}$ & $\begin{array}{l}\text { Tax Credits till } \\
2020\end{array}$ \\
\hline $\begin{array}{l}\text { Extended } \\
\text { Incentives } 2026\end{array}$ & 2026 & Yes & $\begin{array}{l}\text { Pre-2014: Historical Sales Data } \\
\text { 2014-2026: Projections from } \mathrm{MA}^{3} \mathrm{~T} \\
\text { model }\end{array}$ & $\begin{array}{l}\text { AEO } 2014 \text { Reference } \\
\text { Oil Price Case }\end{array}$ & $\begin{array}{l}\text { Tax Credits till } \\
2026\end{array}$ \\
\hline
\end{tabular}

Table 1. Scenario descriptions

\subsection{Electric vehicle market penetration based on consumer choice model}

Based on future energy price and government policy data for the four scenarios discussed in Table 1 , the $\mathrm{MA}^{3} \mathrm{~T}$ model predicts market penetrations for three types of electric vehicles as shown in Figure 2. The market shares are in terms of gasoline passenger car and gasoline passenger truck. The assumption is that electric vehicles are substituting gasoline passenger car and passenger truck given that other fuel type passenger car and passenger truck are accounting for a very small proportion of total fleet. The results indicate the passenger car HEV's market shares will peak in year 2020 and then start declining for all scenarios. It is also found that the projected passenger truck HEV's market shares have been increasing from 2014 to 2026, however, after year 2020, the projected market shares have flatted. On the other hand, the results show plug-in electric vehicles', including PHEV and BEV, market shares have experienced a sharp decrease around year 2020 which is the year tax credits are phasing out. The only 
exception is under "Extended Policy" scenario where the BEV and PHEV's projected market shares are keeping increasing for all timeframe.
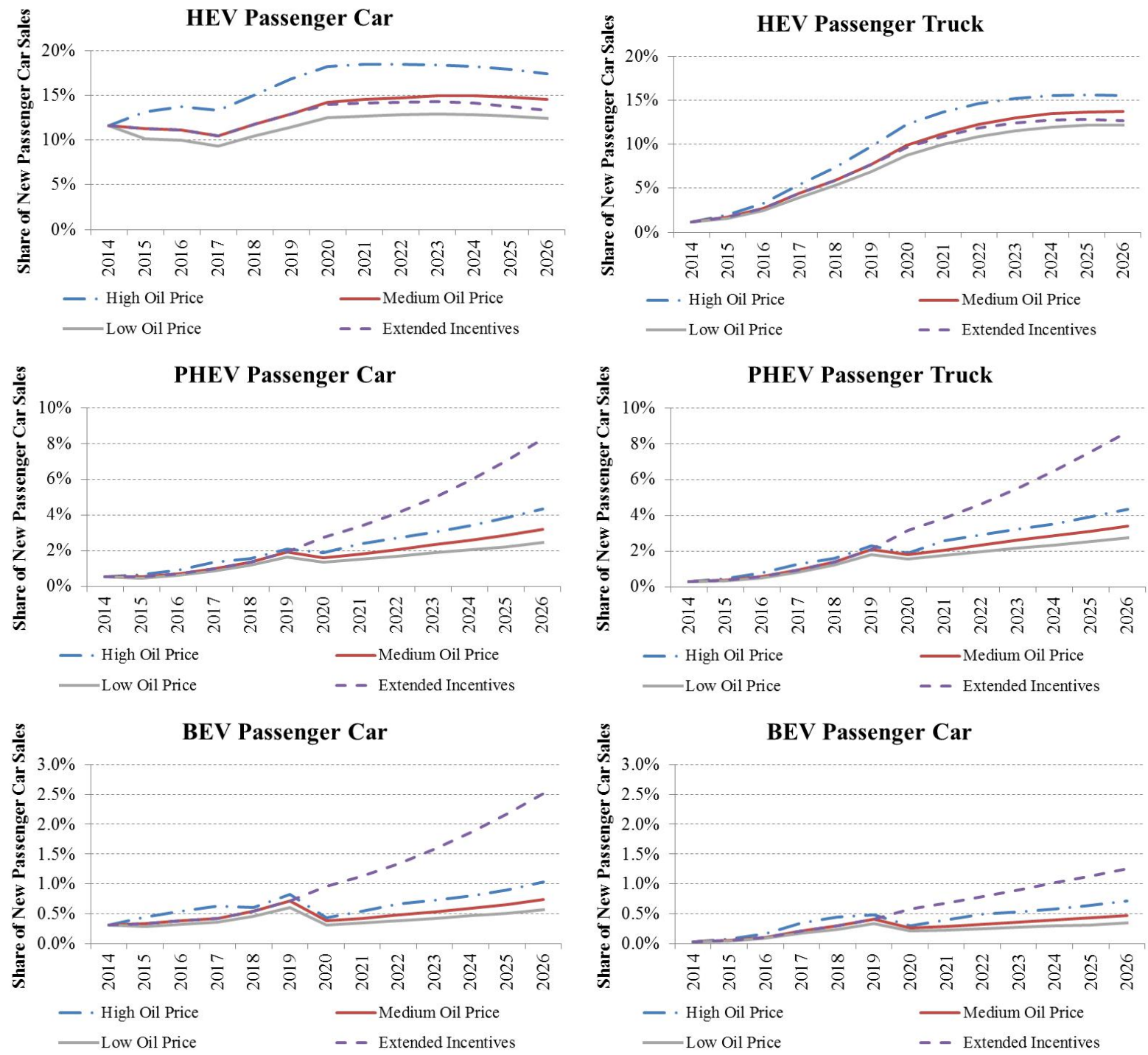

Figure 2; Electric vehicles' market penetration share for different scenarios.

\subsection{Adjustment on VMT mix and emission factors for AFVs}

In order to estimate link-level exhaust emissions, the link-level VMT is distributed into each vehicle type using the VMT mix and then vehicle type specific link-level VMT is multiplied with corresponding emission rates to obtain link-level exhaust emissions estimations. A VMT mix and a set of emission rates are previously developed by TTI researchers for Harris County in year 2026. However, those data consider all vehicle type except AFVs. Based on market shares of AFVs predicted by $\mathrm{MA}^{3} \mathrm{~T}$ model, we develop adjustments to VMT mix to include passenger car and passenger trucks AFVs and in addition, develop fleet average emission rates for each type of AFVs.

EVs' share in VMT mix. In previous section, it is discussed that "MOVESemscalc" calculates link level emission estimates by multiplying hourly link-level VMT with emission rates for each vehicle type and then summing them up by 24 hours of a day and over all links. In this process, we keep VMT mix for all vehicle types, except for passenger car and passenger truck, unchanged. We will divide VMT fraction of passenger car and passenger truck further into conventional vehicles, HEV, PHEV, and BEV of passenger car and passenger truck. The calculation steps are showing below and applied to gasoline passenger car and gasoline passenger truck:

Step 1: Obtain AFV sales data (historical sales till 2014, and sales projects 2014-2026), and GCV population/age 
distribution in year 2014 and 2026 (assumptions see Table 2).

Step 2: Calculate vehicle type/age distribution in year 2014 and 2026, i.e. \% of GCV, HEV, PHEV, and BEV in passenger car and passenger truck.

Step 3: Calculate number of vehicles by type/age in year 2014 and 2026.

Step 4: Obtain vehicle annual VMT by type/age (assumptions see Table 2).

Step 5: Calculate subtotal VMT by vehicle type/age.

Step 6: Calculate VMT share by vehicle type.

EV Emission Factors. After AFV VMT assignment is completed, AFV emission rates in year 2014 and 2026 are needed to calculate emission estimations. Because this study specifically deals with mobile source exhaust emission, therefore, BEV's emission rates are 0 because BEV produces no exhaust emission. In Task 4 of this study, running exhaust emission rates for some HEVs and PHEVs on charging sustaining mode (i.e. engine turned on) are measured by using Portable Emission Measurement Systems. The measured HEVs and PHEVs covered the major brands in the market, therefore, TTI research team used a market share weighted average emission rates to represent emission rates for HEV and PHEV. However, due to sample limit, the representative emission rates for HEV and PHEV are from model year 2012 AFVs in year 2014, i.e. age 2 in year 2014. The emission rates needed to calculate hourly link-level emission estimates are a set of hourly VMT share weighted average emission rates for HEV and PHEV based on vehicle age $0-30$ in year 2014 and 2026. The detailed steps are showing below:

Step 1: Obtain emission rates deterioration trends for HEV and PHEV by model year (assumptions see Table 2).

Step 2: Obtain emission rates trends for year 0 of model year 2014-2026 for HEV and PHEV (assumptions see Table 2).

Step 3: Calculate emission rates for HEV (MY 2000-2014) and PHEV (MY 2010-2014) in year 2014; calculate emission rates for HEV (MY 2000-2026) and PHEV (MY 2010-2026) in year 2026.

Step 4: Obtain VMT share by age for HEV and PHEV in year 2014 and 2026 (from "EV VMT Assignment").

Step 5: Calculate weighted average emission rates for HEV and PHEV fleet in 2014 and 2026 by multiplying corresponding VMT share by age and emission rates by age.

Step 6: Apply the weighted average emission rates for HEV and PHEV fleet to each hour in a day due to lack of hourly AFV emission measurements information in Task 4.

Step 7: Apply a discount rate (0.24 for year 2014 and 0.14 for year 2026) to PHEV emission rates to account for PHEV miles driven by electricity.

\begin{tabular}{|l|l|}
\hline Attributes & Data Source \\
\hline Fuel Attributes & $\begin{array}{l}\text { EPA's latest available (2013) summer season Houston retail } \\
\text { outlet reformulated gas (RFG) survey data used in 2014 and } \\
2026, \text { except sulfur content in 2026 set to 10ppm (Tier 3 rule } \\
\text { annual average standard)* }\end{array}$ \\
\hline I/M Program & $\begin{array}{l}\text { Locality-specific set-ups based on current I/M rules, prior } \\
\text { modeling set-ups and available MOVES I/M parameters* }\end{array}$ \\
\hline Conventional Vehicle Fleet Attributes & $\begin{array}{l}\text { Age Distribution in 2014 and 2026: Harris County mid-year } \\
(2013) \text { TxDOT/DMV vehicle registration*. } \\
\text { Annual Mileage by Age: MOVES2010b default. } \\
\text { Population: Harris County mid-year (2013) TxDOT/DMV } \\
\text { vehicle registration*. }\end{array}$ \\
\hline Electric Vehicle Fleet Attributes & $\begin{array}{l}\text { Annual Mileage by Age: same as conventional vehicle for } \\
\text { HEV and PHEV, half of conventional vehicle for BEV. } \\
\text { Percentage of Miles on electricity for PHEV: } 24 \% .\end{array}$ \\
\hline Meteorology Attributes & \begin{tabular}{l} 
Local, hourly temperature and relative humidity for Harris \\
\hline
\end{tabular}
\end{tabular}




\begin{tabular}{|l|l|}
\hline Link attributes / VMT and Speeds & County based on TCEQ data* \\
\hline Emission Factors Attributes & $\begin{array}{l}\text { HGAC Travel Demand Model processed to reflect summer } \\
\text { weekday travel*. }\end{array}$ \\
& $\begin{array}{l}\text { Conventional Vehicle EFs: MOVES-based EFs based on } \\
\text { Harris County attributes* }\end{array}$ \\
& $\begin{array}{l}\text { Electric Vehicle EFs: Measurements using PEMS equipment } \\
\text { in task 4. (Deterioration trends follow MOVES 2010b default } \\
\text { for conventional vehicle. Zero mile emission rates for new } \\
\text { model year follow MOVES 2010b trends.) }\end{array}$ \\
\hline
\end{tabular}

*Previously prepared by TTI

Table 2. Assumption descriptions

\subsection{Link-based mobile source emission inventory utility}

The adjusted VMT mix, emission rates of all vehicle types along with other parameters as shown in Table 2 are inputted to a link-based emission inventory model, "MOVESemscalc" to estimate on-road exhaust emission for Harris County in year 2026.

"MOVESemscalc" is based on MOVES2010b and is able to estimate daily mobile source emissions at regional level. "MOVESemscalc" calculate emission estimates for a region based on link level emissions using MOVES2010b-based emission rates with local attributes adjustments, travel demand model (TDM) link-based hourly VMT and speeds (summer weekday), and the VMT mix (used to disaggregate the link-level VMT to each of the MOVES source use type/fuel types).

The model utilizes MOVES2010b platform and estimates mobile source daily emission at regional-level based on emission factors with regional adjustments, VMT mix and travel demand model (TDM)-based hourly, summer weekday link VMT and speed distribution (see Figure 2). The model applies VMT mix to link-based VMT and speeds to allocate the link-level VMT to each of the MOVES source use type/vehicle type and then the VMT are applied to emission rates to calculate emissions estimations(TTI Emissions Inventory Estimation Utilities Using MOVES: MOVES2010bUtl User's Guide", TTI, Revised September 2013).

Running exhaust emission factors of $\mathrm{NO}_{\mathrm{x}}, \mathrm{CO}, \mathrm{THC}$, and $\mathrm{CO}_{2}$ were developed based on MOVES2010b with Harris County-specific adjustments (e.g. meteorology, fuel properties, inspection and maintenance program(TTI Emissions Inventory Estimation Utilities Using MOVES: MOVES2010bUtl User's Guide”, TTI, Revised September 2013)). Those emission factors are a function of speed, roadway type, and time of day. There are 16 speed categories, including, 2.5 miles per hour (mph), $5 \mathrm{mph}$ to $75 \mathrm{mph}$ in $5 \mathrm{mph}$ increments. Roadway type categories includes: urban arterial, urban freeway, rural arterial and rural freeway.

The VMT mix specifies the fraction of on-road fleet VMT attributable to each vehicle type by MOVES road type. In this study, the VMT mix is estimated by TTI's 24-hour average VMT mix method which considers Texas Vehicle registration information, Texas Department of Transportation (TxDOT) vehicle classification counts, etc.

Summer weekday hourly, directional, link-VMT and associated average fleet speed are estimated by applying growth/season/hourly allocation adjustment factors, developed by TTI, to Houston Galveston Area of Council (HGAC) travel demand model.

All other attributes are discussed in Table 2. 


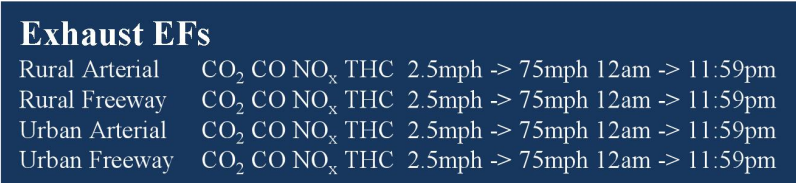

VMT Mix

TDM-Based Hourly, Summer Weekday

Link VMT and Speeds

Link 1: VMT, direction, hourly distribution, Average Speed

Link n: VMT, direction, hourly distribution, Average Speed

\section{Regional Fuel Attributes}

Regional Meteorology Attributes

Regional Inspection \& Maintenance Program

Regional Vehicle Fleet Attributes

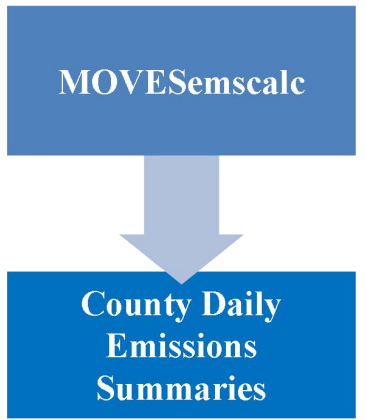

Summaries

Figure 2; Methodology for travel demand model network link-based hourly MOVES emissions estimates.

\section{Results}

\subsection{On-road exhaust emissions impacts of AFVs}

Table 3 presents the number of vehicles for each category under different scenarios. TTI' s previous study has predicted about 2.0 million gasoline PC and 0.6 million gasoline PT in Harris County in year 2026. The projected market shares of AFVs based on MA3T model are used to distribute gasoline PC and PT population into gasoline CV, HEV, PHEV, and BEV. Under AEO 2014 reference energy price scenario, in year 2026, it is predicted that HEV, PHEV, and $\mathrm{BEV}$ account for $11.4 \%, 1.5 \%$ and $0.4 \%$ of the 2.0 million passenger car fleet, and $5.7 \%, 1.2 \%$ and $0.2 \%$ of the 0.6 million passenger truck fleet in Harris County. High oil price scenario will result in increase of HEV, PHEV and BEV, whereas low oil price will result in decrease of three electric vehicle types. Extending tax credit policy to PEV will boost PEV population by $92 \%$ for PC and $93 \%$ for PT.

\begin{tabular}{|l|l|l|l|l|l|l|}
\hline Vehicle Category & Scenario & CV & HEV & PHEV & BEV & Total \\
\hline Gasoline Passenger Car & High Oil Price & $1,668,955$ & 276,878 & 36,696 & 11,119 & $1,993,647$ \\
\hline Gasoline Passenger Car & Medium Oil Price & $1,727,563$ & 228,211 & 29,092 & 8,782 & $1,993,647$ \\
\hline Gasoline Passenger Car & Low Oil Price & $1,759,113$ & 203,162 & 24,055 & 7,316 & $1,993,647$ \\
\hline Gasoline Passenger Car & Extended Policy & $1,698,810$ & 222,083 & 54,176 & 18,579 & $1,993,647$ \\
\hline Gasoline Passenger Truck & High Oil Price & 571,540 & 42,614 & 9,060 & 1,639 & 624,852 \\
\hline Gasoline Passenger Truck & Reference & 580,490 & 35,728 & 7,475 & 1,158 & 624,852 \\
\hline Gasoline Passenger Truck & Low Oil Price & 585,656 & 31,985 & 6,308 & 903 & 624,852 \\
\hline Gasoline Passenger Truck & Extended Policy & 574,571 & 34,650 & 13,398 & 2,233 & 624,852 \\
\hline
\end{tabular}

Table 3. Vehicle Numbers by Category under Scenarios in Year 2026

Figure 4 shows the running exhaust emissions of $\mathrm{CO}_{2}, \mathrm{CO}, \mathrm{NOx}$, THC on an average summer weekday depending on different electric vehicles' penetration. As a trend, high oil price will lead to lower $\mathrm{CO}_{2}$ and $\mathrm{NO}_{\mathrm{x}}$ emission from passenger car and passenger truck, and vice versa. This is because high oil price will result in higher electric vehicle penetration and usually electric vehicles are more energy efficient and emitting less $\mathrm{NO}_{\mathrm{x}}$. On the other hand, high oil price actually induces more $\mathrm{CO}$ and THC emissions. The emission rates for electric vehicles are from PEMS measurements in TTI's previous study. In that study, electric vehicles are tested under a driving cycle which is different from driving cycle to generate emission rates in MOVES. The tested driving cycle has higher engine demand and is constructed to better represent driving behavior in Texas. It was found that the high engine demand driving is leading to higher $\mathrm{CO}$ emission due to inefficient oxidization under high engine temperature. While we acknowledge our testing 
sample might not be representative, it is also important to note we have risks in underestimating certain air pollution by using MOVES default emission factors which is generated by non-representative driving cycle.

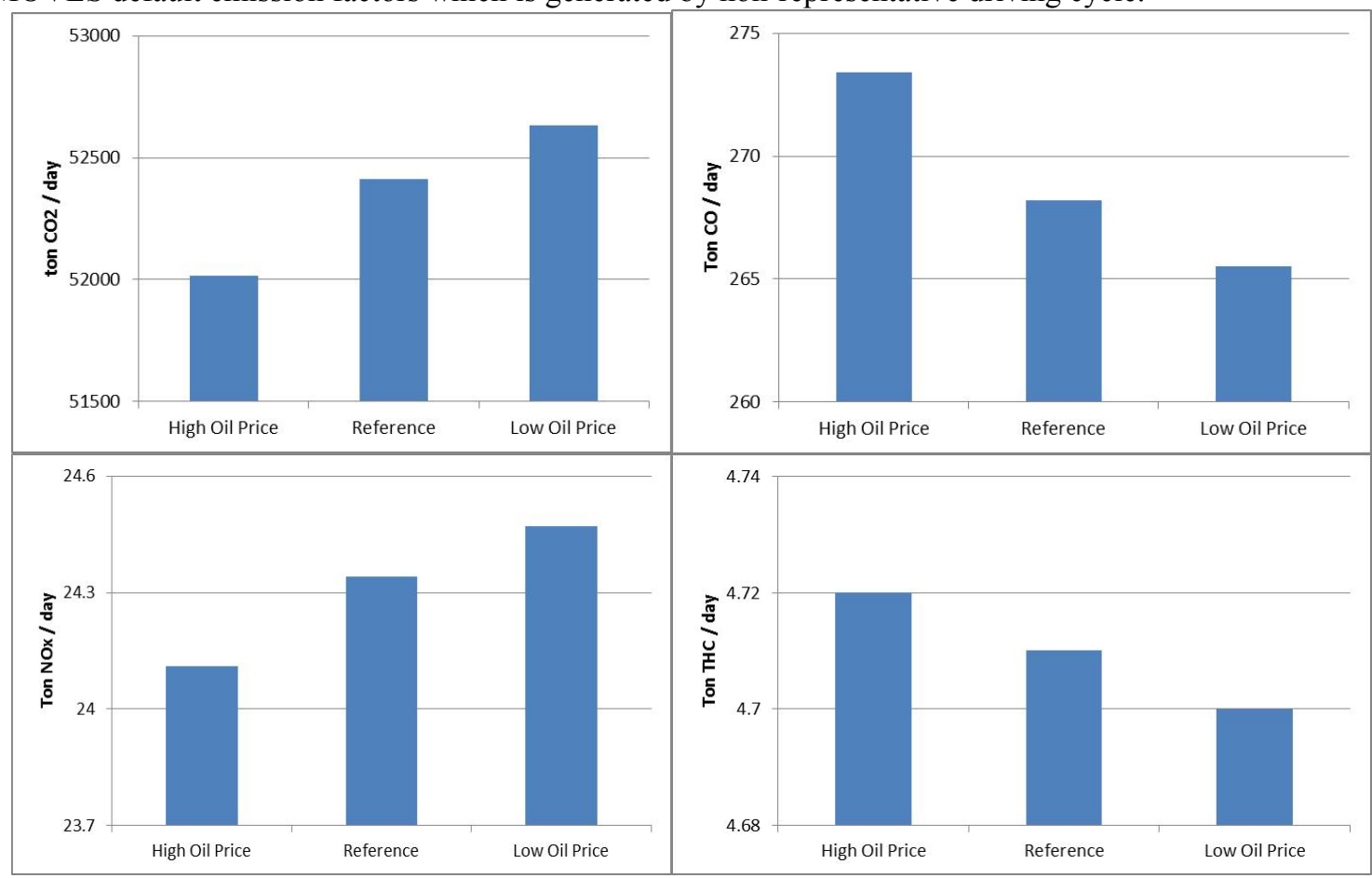

Figure 4; Scenario based summer weekday emission estimations for Harris County in 2026.

\subsection{Cost effectiveness of extended government policy on PEV tax credits}

The framework of this model provides an opportunity to Evaluate cost effectiveness of government incentive policy in electric vehicles. In scenario 4, we try to extend the current tax credits to plug-in electric vehicle until the end of 2026 instead of 2020 under current status. The extended tax credit policy results in increments of 34,881 plug-in electric passenger cars (25,084 PHEV and 9,797 BEV) and 6,997 plug-in electric passenger trucks (5,923 PHEV and 1,075 BEV) between 2020 and 2026. The new added vehicles account for $1.7 \%$ of passenger car and $1.1 \%$ of passenger truck in 2026. It is important to note that the new plug-in electric vehicles are substituting consumers' choices on other types of vehicles. Therefore, the total vehicle population in Harris County in 2026 is not changed. It is calculated that government will spend a total of 73 million 2012 US dollar if the government choose to extend the tax credit for PEV till 2026(0.95 discount rate is used which is also used in $\mathrm{MA}^{3} \mathrm{~T}$ model ).

Compared with medium oil price scenario, the extended incentive policy leads to $641,3.9,0.15$, and 0.05 tons/day reductions in $\mathrm{CO}_{2}, \mathrm{CO}, \mathrm{NO}_{\mathrm{x}}$ and $\mathrm{THC}$ respectively. Assuming 343 summer weekdays' emission to be equivalent to annual emission, the government spending by extending the PEV tax credit policy would be $\$ 485, \$ 79,764$, $\$ 2$ million, and $\$ 6$ million for reducing 1 ton of $\mathrm{CO}_{2}, \mathrm{CO}, \mathrm{NOx}$, THC in year 2026.

\section{Conclusion}

This study proposes a framework to evaluate AFV's regional air quality impacts by integrating endogenous consumer choice model and MOVES-based regional emission inventory model. The advantage of this framework is being able to assess dynamics of AFV market penetration due to future energy price and government policy. A case study is conducted on Harrison County at Houston Metropolitan area.

The results indicate that high energy price would induce more electric vehicle purchase and potentially change GHG and criteria pollutants emission from passenger car and passenger truck. We have to acknowledge that the emission estimations are based on electric vehicle emission factors measured by PEMS testing conducted on a sample of vehicles. The testing driving cycle is different from driving cycle used for obtaining emission factors in MOVES 
model. Given the testing driving cycle is constructed with aim to be representative of driving behavior in Texas, it is again means the driving cycle in MOVES model might not be representative to the real-world driving.

The main contribution of this study is to establish a framework that can be used to incorporate AFVs in conformity type analysis. Through a Harris County case study, we demonstrate that by integrating in-use AFVs emission measurements, endogenous vehicle consumer choice model, and Link-based emission model, AFVs' emission impacts could be captured and we could potentially reduce misestimate of emission estimations. Our emphasis is on the development of a framework which could utilize current models with some adjustment on AFVs VMT and emission rates. The exact numbers reported in this case study are less emphasized and shall be used with caution when directly referred to. This is because the results are case specific, and are based on inputs that are subject to arguments, especially parameters related to AFVs' emission deterioration effects. We shall also point out several limitations of this study for future research. First of all, we focused only on on-road exhaust emissions which are part of the total emissions from transportation sector. Start emissions, idling emissions, off-road emissions are not included in this study. Introducing electric vehicles might reduce those emissions but without enough data for emissions performance of electric vehicles, it is difficult to quantify AFV's impact. Secondly, the AFVs' exhaust emissions rates are based on limited in-use measurements of AFVs. Both the number of AFVs measured and tested driving conditions might not be representative to the real-world situation.

\section{References}

1. Baptista P, Tomas M, Silva C. Plug-in hybrid fuel cell vehicles market penetration scenarios. International Journal of Hydrogen Energy 2010; 35(18): 10024-10030.

2. CARB, 2014. Zero emission vehicle program. Accessed on May 15 ${ }^{\text {th }}, 2014$. Avaliable from: http://www.arb.ca.gov/msprog/zevprog/zevprog.htm.

3. Chen Y, Fan Y, Transportation fuel portfolio deisgn under envolving technology and regulation: A California case study. Transportation Research Part D 2013; 24: 76-82.

4. European Parliament, 2011. 2014 Directorate-General For Internal Policies. May $11^{\text {th }}, 2014$. Avaliable from: http://www.europarl.europa.eu/document/activities/cont/201106/20110629ATT22885/20110629ATT22885EN.pdf.

5. EPA. 1970-2013 Average annual emissions, all criteria pollutants in MS Excel. National Emissions Inventory (NEI) Air Pollutant Emisions Trends Data. Accessed on 15 May 2014. Avaliable from: http://www.epa.gov/ttn/chief/trends/index.html.

6. EPA, n.d. Source of greenhouse gas emissions. Accessed on May 11 ${ }^{\text {th }}, 2014$. Avaliable from: http://www.epa.gov/climatechange/ghgemissions/sources/transportation.html.

7. Farzaneh R, Zietsman J.A, Lee D, et al. Texas-specific drive cycles and idle emissions rates for using with EPA's MOVES model-final report. 0-6763-1; Texas A\&M Transportation Institute: College Station, TX, April, 2014.

8. Ford A 1995. The impacts of large scale use of electric vehicles in southern California. Energy and Buildings 1995; 22(3): 207-218.

9. Hawkins T. R, Gausen O.M, Strømman A.H. Environmental impacts of hybrid and electric vehicles: A review. The International Journal of Life Cycle Assessment 2012; 17(8): 997-1014.

10. Haghani A, Hamedi M, Sadabadi K, et al. Data collection of freeway travel time ground truth with bluetooth sensors. Transportation Research Record: Journal of the Transportation Research Board 2010; (2160): 60-68.

11. IEA. $\mathrm{CO}_{2}$ Emissions from Fuel Combustion. Accessed on July $1^{\text {st }}, 2014$. Avaliable from: http://www.iea.org/publications/freepublications/publication/co2emissionsfromfuelcombustionhighlights2013.pdf.

12. Kammen D.M, Arons S.M, Lemoine D, et al. Cost-effectiveness of greenhouse gas emission reductions from plug-in hybrid electric vehicles. Environment 2002; 7(2): 155-162.

13. Kim J.D, Rahimi M. Future energy loads for a large-scale adoption of electric vehicles in the city of Los Angeles: Impacts on greenhouse gas (GHG) emissions. Energy Policy 2014, in press.

14. Millo F, Rolando L, Fuso R, et al. Real $\mathrm{CO}_{2}$ emissions benefits and end user's operating costs of a plug-in hybrid electric vehicle. Applied Energy 2014; 114(114): 563-571.

15. Morrison G, Chen Y, 2011. Uncertain future for California's low-carbon fuel standard. Transportation Research Record. Journal of the Transportation Research Board 2011; 2252(1): 16-22.

16. Lin Z, Greene D. A plug-in hybrid consumer choice model with detailed market segmentation. Paper presented at the $89^{\text {th }}$ Annual Meeting of Transportation Research Board, Washington, DC, 2010.

17. Nichols G, Kockelman M., Reiter, 2009. Air quality impacts of electric vehicle adoption in Texas. Working paper.

18. Propfe B.D, Kreyenberg J, Wind S, et al. Market penetration analysis of electric vehicles in the German passenger 
car market towards 2030. International Journal of Hydrogen Energy 2013; 38(13): 5201-5208.

19. Thompson T.M, King C.W, Allen D.T, et al. Air quality impacts of plug-in hybrid electric vehicles in Texas: Evaluating three battery charging scenarios. Environ Res Lett 2011; 6(2): 4004.

20. U.S. Department of Energy (DOE), 2011. One MILLION electric vehicles by 2015. May $11^{\text {th }}, 2014$. Avaliable from: https://www1.eere.energy.gov/vehiclesandfuels/pdfs/1_million_electric_vehicles_rpt.pdf.

21. Yabe K.Y, ShinodaT, Seki H, et al. Market penetration speed and effects on $\mathrm{CO}_{2}$ reduction of electric vehicles and plug-in hybrid electric vehicles in Japan. Energy Policy 2012; 45: 529-540.

22. Yang S.J, Yao T, Kang X, et al. Dynamic operation model of the battery swapping station for AFV (electric vehicle) in electricity market. Energy 2014; 65(1): 544-549.

23. Zhou G.X, Ou X, Zhang,. Development of electric vehicles use in China: A study from the perspective of life-cycle energy consumption and greenhouse gas emissions. Energy Policy 2013; 59: 875-884.

24. Tal G, Nicholas M.A, Davies J, et al. Charing behavior impacts on electric VMT: Who is not plugging in? Transportation Research Record 2014.

25. Idaho National Laboratory. The AFV Projects Summary Reports. http://avt.inl.gov/pdf/EVProj/VoltPercMiinEVModeAug2013.pdf. Accessed on June 1st, 2014.

26. Pike E. Calculating electric drive vehicle greenhouse gas emissions. Vehicle Electrification Policy Study Task 5 Report by International Council on Clean Transportation. http://www.theicct.org/sites/default/files/publications/ICCT_CalculatingEdriveGHG_082012_0.pdf. Accessed on June $4^{\text {th }}, 2014$.

27. Chevy Volts online forum. http://www.voltstats.net/. Accessed on May 4th, 2014. 